Ranadewa, K.A.T.O., Sandanayake, Y.G. and Siriwardena, M.L., 2019. Lean enabling human capacity building of small and medium contractors in Sri Lanka. In: Sandanayake, Y.G., Gunatilake, S. and Waidyasekara, A. (eds). Proceedings of the $8^{\text {th }}$ World Construction Symposium, Colombo, Sri Lanka, 8-10 November 2019, pp. 400-410. DOI: doi.org/10.31705/WCS.2019.40. Available at: https://2019.ciobwcs.com/papers

\title{
LEAN ENABLING HUMAN CAPACITY BUILDING OF SMALL AND MEDIUM CONTRACTORS IN SRI LANKA
}

\author{
K.A.T.O. Ranadewa ${ }^{1}$, Y.G. Sandanayake ${ }^{2}$ and M.L. Siriwardena ${ }^{3}$
}

\begin{abstract}
Lean construction is still at the premature stage of the small and medium contractors (SMCS) in Sri Lanka. Lack of focus on human capacities required to implement lean has hindered its implementation. Thus, human capacity building is a paramount factor for successful lean implementation of SMCs in Sri Lanka. However, there is a lack of empirical investigation on human capacities and strategies to build human capacities for lean implementation in Sri Lankan SMCs. This paper investigates the lean enabling human capacities and strategies, and hence develops a framework to build those human capacities for successful lean implementation in Sri Lankan SMCs. The research adopts interpretivism stance and uses the qualitative survey strategy. The empirical data collection technique adopted is semi-structured interviews with 24 experts who are having experiences both in SMCs and lean implemented projects. The code based content analysis was used as the data collection technique, which was supported by NVivolo and interactive data visualisation tool, Power Bi was used to present the analysed data. The research identified team working skills, critical thinking, leadership, communication skills, work ethics, knowledge and positive attitudes as lean enabling human capacities in SMCs. Training, learning and using existing capacities were identified as the most significant individual level strategies, where education and training, and financial support for SMCs were recognised as strategies that can be used by external environment entities to build the above capacities. The developed framework further highlighted that use of existing capacities, proper recruitment, proper investments, networking, maintain a lean culture and learning by doing as organisational strategies to build the lean enabling capacities. Industry practitioners can use this framework to develop lean enabling human capacities in order to accelerate the lean implementation in Sri Lankan SMCs.
\end{abstract}

Keywords: Human Capacity Building; Lean Construction; Small and Medium Contractors; Sri Lanka.

\section{INTRODUCTION}

Small and medium contractors (SMCs) are well-known for the increase of non-value adding activities (NVAA) in construction industry (Tazel et al., 2017; Ranadewa et al., 2018). This has highlighted the importance of SMCs to implement lean and reduce the NVAA among their projects. Yet, implementation of lean among SMCs is not free from

\footnotetext{
${ }^{1}$ Department of Building Economics, University of Moratuwa, Sri Lanka, tharushar@uom.lk

2 Department of Building Economics, University of Moratuwa, Sri Lanka, ysandanayake@uom.lk

${ }^{3}$ Department of Built Environment, Liverpool John Moores University, United Kingdom, m.1.siriwardena@1jmu.ac.uk
} 
barriers (Ankomah et al., 2017; Rymaszewska, 2014) and thus, the researchers highlighted the need of enhancing human capacities for successful lean implementation. Although, Ranadewa et al., (2017) highlighted that human capacity building as a key to success in lean implementation among SMCs in Sri Lanka, there is a lack of research with this regard. Thus, the aim of this study is to develop a framework to build lean enabling human capacities in Sri Lankan SMCs. The objective of the research is to investigate lean enabling human capacities and identify the strategies to build them by the SMCs. This paper begins with a literature review on why lean implementation fails in and the need of building lean enabling human capacities. The next section discusses the methodology used in this study. The findings of the research are presented under lean enabling human capacities and strategies for building those human capacities. Finally, a framework for lean enabling human capacities is developed for SMCs in Sri Lanka.

\section{LITERATURE REVIEW}

\subsection{WHY LEAN IMPLEMENTATION FAIL?}

Applying lean concept by construction organisations and construction projects during both design and construction phases is becoming an important trend. Prior studies reveal that SMCs do not have the capacity to implement lean concept (Chiarini, 2012; Ankomah et al., 2017). SMCs and the industry as a whole, have been criticised by many researchers for limited collaborative working philosophies, slow uptake of new technologies and processes and issues with organisational management (Miller et al., 2002). Considering the investment levels of the construction industry and the development needs of most developing countries, attention to these matters is long overdue. SMCs constitute the largest group in the construction industry and their performance impacts greatly on the performance of the industry. Nevertheless, there is a significantly lower rate of adoption of lean principles by SMCs than by large contractors (Rymaszewska, 2014). Moreover, most of the SMCs are still unfamiliar with lean concept (Ankomah et al., 2017; Rymaszewska, 2014).

According to lean construction deployments of SMCs, unlike the manufacturing industry, the researches that investigate lean in SMCs has remained scarce (Zhou, 2016; Antosz and Stadnicka, 2017). Although Rymaszewska (2014) and Chiarini (2012) highlighted the importance of implementing lean in SMCs, it is still at its infancy. Tasel et al. (2017) differentiated the current status and future direction of lean construction in SMCs and stated that unavailability of implementable framework focusing on individuals of the SMCs have hinder the lean implementation. Although the challenges of lean implementation in construction and solutions to overcome them have been previously explored (Shang and Pheng, 2014; Aziz and Hafez, 2013) even in Sri Lanka (Senaratne and Wijesiri, 2008; Senaratne et al., 2010), there is a dearth of research on lean implementation and how to overcome the barriers of lean implementation in Sri Lanka through proper management of individuals in SMCs in Sri Lanka.

According to Koskela et al. (2014), lean construction requires changes in individual behaviour. Thus, building individual capacities will accelerate the lean implementation. Simultaneously, building capacities for successful lean implementation will add a value for SMCs to better perform in the industry. Hence, SMCs must identify necessary capacities to obtain the full benefit of lean implementation. However, lean is not just a set of tools and techniques, but its heart is the people (Bhasin, 2012). It is the people, 
whose knowledge, intelligence and desire to improve that steers organisations to new levels of continuous improvement (Bhasin, 2012). Therefore, lean relies heavily on the knowledge and skills of the people and how they respond to changes (Sawhney and Chason, 2005). Hence, the transformation towards lean construction will lead to changes in the culture and in its people (Green et al., 2008) and thus require a considerable reflection on human capacity building for successful lean implementation.

\subsection{Lean ENABLing Human CAPACITIES}

Human capacity refers to the will and ability of an individual to set objectives and to achieve them using one's own knowledge and skills (Matachi, 2006). However, Kululanga (2012) specified that contributions at this level in capacity building for construction industry refer to how individuals in the industry are equipped with relevant education, training and continual professional development. Nevertheless, OECD (2012) defined individual capacity as knowledge and skills to set and achieve objectives. These capacities explicitly focus on skill development, building stronger relationships, knowing how, knowing what and co-creation of meaning and understanding (Preskill and Boyle, 2008). Similarly, Enemark and Ahene (2002) identified human resources in terms of knowledge, skills, personal and group attitudes for developing and managing certain areas, which ensure long-term sustainability.

Although many researchers have discussed about human capacities in the construction industry, there is a lack of studies focusing on human capacities required for successful lean implementation. Table 1 presents the capacities highlighted by the researchers as required for successful lean implementation.

Table 1: Human capacities required for successful lean implementation

\begin{tabular}{|c|c|c|c|c|c|c|c|c|c|c|c|c|}
\hline \multirow{2}{*}{$\begin{array}{l}\text { Human Capacities Necessary } \\
\text { for Lean Implementation }\end{array}$} & \multicolumn{12}{|c|}{ References } \\
\hline & 1 & 2 & 3 & 4 & 5 & 6 & 7 & 8 & 9 & 10 & 11 & 12 \\
\hline Knowledge & $\mathrm{x}$ & $\mathrm{x}$ & $\mathrm{x}$ & $\mathrm{x}$ & $\mathrm{x}$ & & $\mathrm{x}$ & $\mathrm{x}$ & & $\mathrm{x}$ & $\mathrm{x}$ & $\mathrm{x}$ \\
\hline Relevant education & $\mathrm{x}$ & $\mathrm{x}$ & $\mathrm{x}$ & $\mathrm{x}$ & $\mathrm{x}$ & & $\mathrm{x}$ & $\mathrm{x}$ & $\mathrm{x}$ & $\mathrm{x}$ & & \\
\hline Technical skills & & $\mathrm{x}$ & & & $\mathrm{x}$ & & & & & & $\mathrm{x}$ & $\mathrm{x}$ \\
\hline Managerial skills & $\mathrm{x}$ & $\mathrm{x}$ & & & $\mathrm{x}$ & & $\mathrm{x}$ & $\mathrm{x}$ & $\mathrm{X}$ & $\mathrm{X}$ & & \\
\hline Values and attitudes & $\mathrm{x}$ & $\mathrm{x}$ & & $\mathrm{x}$ & & & & & & $\mathrm{X}$ & & $\mathrm{x}$ \\
\hline $\begin{array}{l}\text { Willingness to set and achieve } \\
\text { objectives }\end{array}$ & & $\mathrm{x}$ & & & & $\mathrm{x}$ & & & & & & \\
\hline Capacity to build relationships & $\mathrm{X}$ & & $\mathrm{X}$ & & $\mathrm{x}$ & & $\mathrm{x}$ & & & & & \\
\hline Trust and legitimacy & & $\mathrm{X}$ & & & & & & & & & & \\
\hline Experience & $\mathrm{x}$ & $\mathrm{x}$ & & $\mathrm{x}$ & & $\mathrm{x}$ & & $\mathrm{x}$ & & & & $\mathrm{x}$ \\
\hline Sufficient training & $\mathrm{x}$ & $\mathrm{X}$ & $\mathrm{x}$ & $\mathrm{x}$ & $\mathrm{x}$ & $\mathrm{x}$ & $\mathrm{x}$ & $\mathrm{x}$ & $\mathrm{x}$ & $\mathrm{x}$ & & $\mathrm{x}$ \\
\hline $\begin{array}{l}\text { Continual professional } \\
\text { development }\end{array}$ & $\mathrm{x}$ & & & & & $\mathrm{x}$ & & & & & $\mathrm{X}$ & \\
\hline
\end{tabular}

Sources: (1) Achanga et al., 2006; (2) Alves et al, 2016; (3) Ankomah et al., 2017; (4) Antosz and Stadnicka 2017; (5) Tazel et al., 2017; (6) Basil, 2007; (7) Chiarini, 2012; (8) Ranadewa et al., 2017; (9) Dora and Gellynck, 2015; (10) Jin and Ling, 2005; (11) Kululanga, 2012; (12) Rymaszewska, 2014 
Accordingly, many researchers agreed that sufficient knowledge and relevant education are paramount for individuals in SMCs. Similarly, they required to improve the managerial and technical skills through a proper training to accelerate lean implementation. One of the lean implementation barriers identified by several researchers (Tazel et al., 2014; Shang and Pheng, 2014), is the resistance to change by SMCs. Thus, proper values and attitudes are required among the individuals of the organisation. They further specified that access to resources and experiences that can develop individual capacity are largely shaped by the organisational and environmental factors, which in turn are influenced by the degree of capacity development in each individual. Kululanga (2012) and Lopes and Theisohn (2003) focused on human capacity building for successful lean implementation. They identified training individuals as a strategy to improve the required lean capacities. Kululanga (2012) and Karunasena and Amaratunga (2016) further included specific trainings such as training aligned to construction industry needs, life-long learning driven by an individual employee within a firm, training for individual employees supported by a construction firm or the industry for construction workforce as some of other strategies for building lean human capacities. Similarly, construction organisation as well as the external environment needs to support in building lean enabling human capacities.

\section{METHODOLOGY}

This research aimed to develop a framework to build lean enabling human capacities in SMCs in Sri Lanka. A literature review was carried out to explore the theoretical identification. There is a need to ascertain different views of the experts with regards to SMCs on lean enabling human capacities and human capacity building strategies in Sri Lankan context. Therefore, the study valued and encouraged the free flow of ideas, opinions, perceptions and experience of people within the research environment thus, considers the human interaction as the main driver of the study. Hence, the study skewed the ontological assumption of 'reality is not pre-determined, but socially constructed' and the epistemological assumption of 'the knowledge is gathered by examining the views of the people' as per Saunders et al. (2009). Similarly, in terms of the axiology, the study takes the value laden stance as it is believed that the researcher would add value to the study. Thus, the research is in line with the interpretivism stance.

The research strategy followed by the study is 'qualitative survey strategy'. The empirical data collection technique adopted is semi-structured interviews with experts in Sri Lanka selected through purposive sampling. Employing semi-structured interview method is preferred in qualitative approach since the respondents have a structured flow to ask questions from interviewees. 24 experts, who are having experiences both in SMCs and lean implemented projects in Sri Lanka were interviewed as per Mason (2010)'s suggestion on the sample sizes. Interviewees included Managing Directors and a Chairmen of SMCs, lean consultants, Senior Project Managers and Senior Quantity Surveyors, who have more than 20 years' experience in the construction industry.

The code based content analysis was used to produce a uniform schema of categories, which facilitated the comparison (Flick, 2009) and NVivo10 was used to analyse the data, which can help to organise, explore and speed up the time taken for doing the data analysing of unstructured data. Further, interactive data visualisation tool, Power Bi was used to present the analysed data through the final framework of the research. 


\section{RESEARCH FINDINGS}

This study investigated the human capacities necessary for enabling lean and strategies to build lean enabling human capacities in SMCs. Following sub-sections elaborate findings of this research study.

\subsection{LEAN ENABLING HUMAN CAPACITIES IN SMCS}

The human capacities that enable lean in SMCs were asked during the interviews with experts. Many of the respondents specified that proper verbal, non-verbal and visual 'communication skills' of employees are essential for lean implementation within the SMCs. Similarly, critical analysis of a problem and deriving a solution are crucial for continuous improvement. Hence, lean experts suggested 'critical thinking' as one of the most important capacities that need to be improved by employees. People need to be adoptable for the changing conditions. Hence, there is a requirement to think out of the box. One of the important lean capacities that individuals in SMCs should have is the 'leadership' which has a major role to play in the individual lean capacity lexicon. The leader needs to be accountable, appreciate people, drive changes, motivate and shares the big picture with others. The respondents added proper conflict management and willingness to help as essential qualities of a leader. However, leadership is not limited to the top or middle management. Even the shop floor level workers must become selfleaders. Therefore, there is a need to change the working philosophy. It is necessary to change the way people think and the way people approach the project. This necessitate building up 'positive attitudes' among the individuals. Many parties need to be effectively involved to be succeeded with the lean implementation. It requires different level of attentions to detail than what the rule of thumb target and hence required proper 'team working'. Employees need to be collaborative, accept feedback and should have the capacity to handle challenging situations. Moreover, there is a need to establish interpersonal relationships and networking with the team members.

Workers need to be dedicated, highly organized, reliable, resilient and results oriented. The respondents added that workers need to be self-directed, self-monitoring, selfsupervising, stay on task and trainable to achieve the objectives of the lean implementation. Otherwise, lean implementation will fail in the initiation stage. Therefore, corporate 'work ethics' can be identified as another category of human lean capacities of SMCs. One of the major lean implementation barriers is the lack of lean awareness within the organisation. Therefore, lean consultants especially highlighted the need of lean knowledge and the technical know-how for SMCs. They need to be trained to ascertain knowledge by doing and get sufficient training. Thus, ability to learn by doing and applying what is learnt is important. Moreover, top management should not be very conservative when recruiting employees and must ensure that the selected employees are qualified not only with relevant education. Hence, 'sound knowledge' is identified as another individual lean enabling capacity for individuals in SMCs.

Therefore, communication skills, critical thinking, leadership, positive attitudes, team working and work ethics can be identified as lean enabling human capacities in SMCs where literature incidentally agreed. Yet, most of the researchers (Tazel et al., 2017, Ankomah et al., 2017, Alves et al., 2016, Ranadewa et al., 2017) agreed that knowledge is an essential capacity that enables lean among SMCs. 


\subsection{Strategies to Build Lean EnAbling Human Capacities}

The following sections present the strategies that individuals, organisations and external environment parties can use to build the above identified lean enabling human capacities of SMCs in Sri Lanka as identified by the experts.

\subsubsection{How can Individuals Build Lean Enabling Human Capacities?}

The respondents highlighted the importance of getting proper training for employees of the organisation. As SMCs are having few numbers of employees, providing training for them is stress-free compared to large contractors. However, to build up lean capacities, SMCs should encourage their employees as well as top management to be trained in order to improve their ability to perform functions. It necessitates encouraging employees to be vigilant to identify the available programs and attend them to gather knowledge. The respondents further added that most of the government programs are conducted free of charge or at very low rates for SMCs. Therefore, they need to get the benefit of being SMCs in the construction industry. However, the respondents added the importance of attending CPDs to get lean awareness. Therefore, continuous 'training' marked as an individual level strategy. One of the major characteristics of lean implemented organisations is continuous urge on 'learning'. All the respondents had unanimously agreed that there are good learning opportunities available in the construction industry, which will support SMCs in building lean human capacities. Development of soft skills will improve the problem solving skills of employees. Similarly, SMCs can 'develop soft skills' by attending in-house trainings on corporate etiquette. As discussed in section 2.1, the most difficult factor to change is the mind set of people. The respondents agreed the need of motivation requirement to change the attitudes of people in SMCs. Thus, there is a need to analyse the ways of motivating the workers to change their attitudes towards lean implementation. During the interviews, lean experts clearly indicated the importance of 'start lean' with pilot projects. Therefore, SMCs first need to make better 'use of existing capacity' to start lean implementation. Thus, the individuals required to develop their existing capacities in the first instance to encourage the lean implementation. Further, SMCs need to 'monitor and report the individual progress' in continuous improvement. The continuous improvement of processes will demonstrate the achievability of these individual level lean capacities. Nevertheless, all the respondents undeniably stressed the importance of proper strategies for SMCs to build individual lean capacities.

\subsubsection{How can Organisation Build Lean Enabling Human Capacities?}

As SMCs lack human resources, there is a need to employ the best in order to get the maximum benefit to the organisation. One of the respondents from top management highlighted that there is a need to recruit qualified people who are practical in nature. Thus, top management has to play a vital role with this regard during the recruitment process. Respondents emphasised the need of having a lean expert in the organisation. This person will be the change agent for the organisation who can develop the pathway towards proper lean implementation. Therefore, to gain more benefits within the organisation, experts suggested that top management need to promote research and development in the organisation. Although, research and development marked as one of the ways to build lean capacities, single handed researches cannot be taken as the best practices within the organisation. Hence, the respondents articulated that a group of people would be ideal for researching to develop the capacities. Hence, as an initiation, 
they need to pursue partnerships in working with others in the organisation. Thus, there is a need to encourage networking. Correspondingly, organisations need to rethink the usage of existing capacities for building new capacities. According to the research findings, many lean experts expressed the need of proper financial allocation to build the lean enabling human capacities.

Most of the individual lean capacities can be achieved through maintaining a lean culture within the organisation thus required to maintain a culture for improvement and a noblame culture. Similar to strategies at individual level, training, learning by doing, starting lean with pilot projects and monitor and report the progresses of SMCs will help to build lean enabling human capacities.

\subsubsection{How can External Environment Entities Build Lean Enabling Human Capacities?}

The respondents agreed that lean enabling human capacity building in SMCs can be driven by the construction industry, including Construction Industry Development Authority (CIDA), non-government institutes, professional institutes, large construction organisations as well as the government. Educating and training of construction workforce is one of the prominent strategies that can be accelerated to build lean enabling human capacities. Although there is a need to increase the number of training programs, one of the respondents doubted about the quality of these training programs conducted at the construction industry level. Many respondents contended the lack of continuous professional development in the construction industry. Thus, construction industry needs to take necessary actions to encourage the professional development. Moreover, human capacities can be built by encouraging inter/intra-industry research activities. The construction industry can encourage dissemination and exhibitions of research activities. The research conducted on lean construction need to be publicised to identify the new trends and solutions offered for lean constructions. This can be achieved through conducting research conferences. Respondents specified the importance of developing a code of good working practice for sites and SMCs and particularly developing a lean code of conduct for SMCs. Therefore, this code of conduct will guide SMCs in proper implementation of lean concept.

Similarly, the experts highlighted that the government must financially support the SMCs for lean implementation. The government can allocate funds for lean awareness programmes and provide loans at concessional interest rates for SMCs who try to implement lean by considering the monetary and fiscal policies of the government.

\section{DISCUSSION OF FINDINGS}

As the final step, this research mapped lean enabling human capacities with the strategies required for building those capacities. Figure 1 presents the summary of findings.

According to Figure 1, lean enabling human capacities such as critical thinking, positive attitudes and work ethics can be improved by attending the in-house trainings on corporate etiquette programs. Moreover, they can attend training programs available for individual employees supported by large construction firms. Moreover, non-government organisations as well as construction institutes are willing to assist SMCs with the help of large construction firms to implement lean in order to develop the industry as whole. 


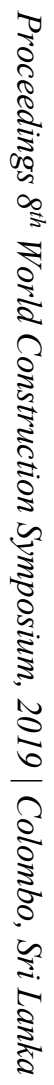

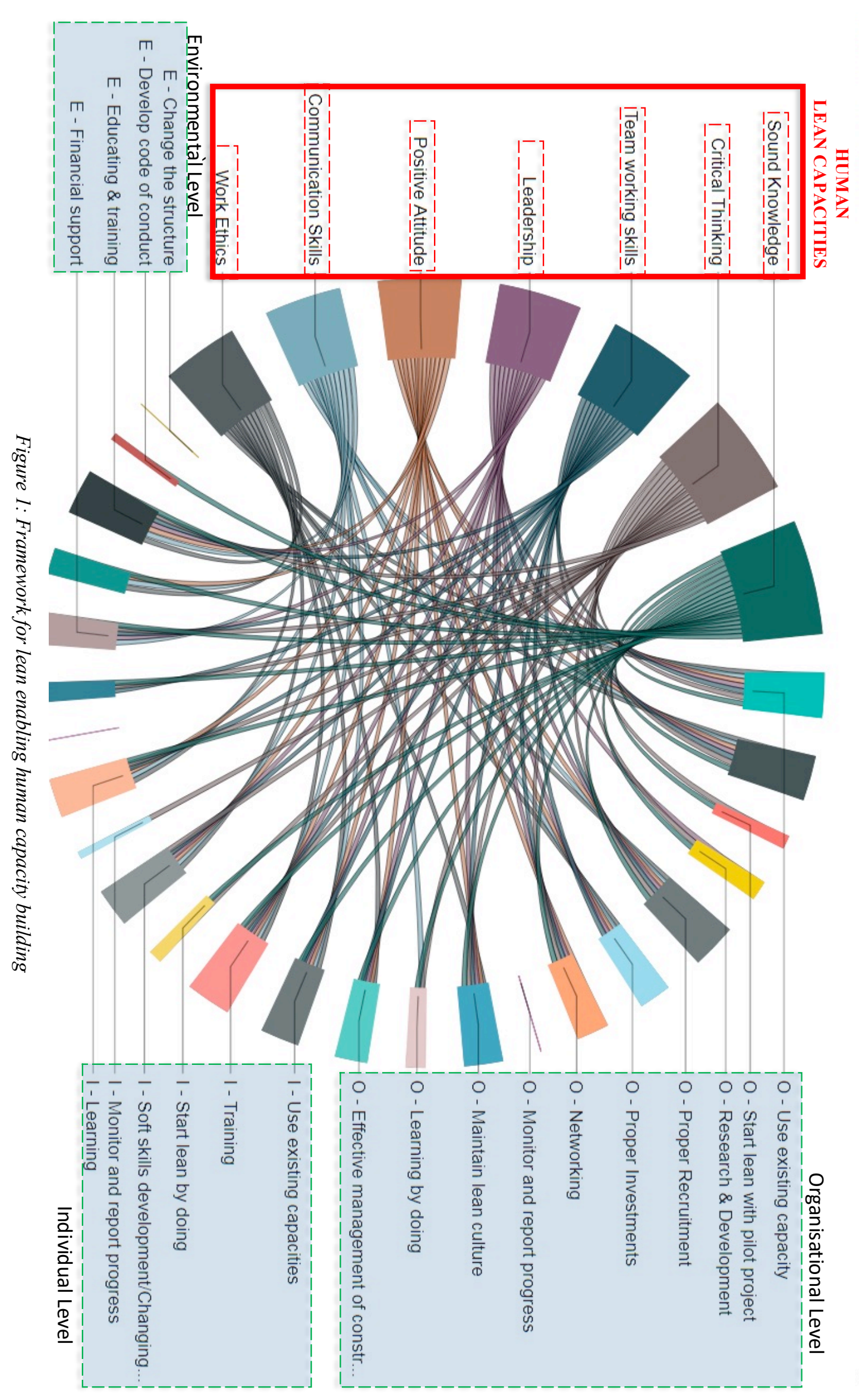

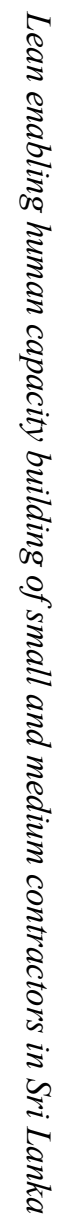


Moreover, employees can attend training programs, which help improving their soft skills, leadership qualities, team working skills and communication skills. This was further proven by Lopes and Theisohn (2003) in literature. Moreover, training sessions are paramount to improve lean capacities such as critical thinking, positive attitudes and work ethics. Thus, training, soft skills development and start lean by doing counted as the most critical factors to be considered in building lean enabling human capacities of SMCs.

As suggested by Kululanga (2012) and Karunasena and Amaratunga (2016) the employees must get proper learning through training. Hence, voluntary learning, with genuine commitment and interest will ensure that the individuals are packed with required lean capacities. Hence, experts admired continuously maintaining the acquired skills and knowledge to build lean human capacities. Conversely, they suggested the development of new capacities among the available workers at site rather recruiting new workers for the site. Yet, there is a need of organisational and external environmental entity capacities to get the maximum use of existing individual capacities. SMCs must have good knowledge on lean capacities required for their projects. Thus, they can build or strengthen existing capacity to implement new lean tools and techniques. However, the findings highlighted that progress monitoring after attending lean awareness programs is important. Yet, it is difficult to check the progress after attending skill development program. It is time consuming and organisations need to maintain a proper mechanism to monitor and report the progress of individuals in the firm. Nevertheless, SMCs as well as the external environment entities can help to build the required lean enabling human capacities. Therefore, in order to enhance the knowledge of the individuals, most of the aforementioned strategies have to be followed up.

\section{CONCLUSIONS}

There has been a notable growth in lean implementation in construction industry. To implement lean in SMCs, there is a need to identify the lean enabling human capacities. This paper investigated the lean enabling human capacities for SMCs and the strategies to build the identified capacities. This study identified critical thinking, leadership, positive attitudes, team working skills, work ethics and sound knowledge as the lean enabling human capacities for SMCs in Sri Lanka. Hence, the research findings will guide SMCs to explore the required lean enabling human capacities of SMCs in Sri Lanka. However, these capacities need to be built with the help of individuals, SMCs as well as the external environment entities. Training, learning and using existing capacities were identified as the most significant individual level strategies, where education and training, and financial support for SMCs were recognised as the strategies that can be used by external environment entities to accelerate the lean implementation. The findings further highlighted that use of existing capacities, proper recruitment, proper investments, maintain lean culture, networking, and learning by doing as organisational strategies to build the identified lean enabling capacities. The framework developed in this study will guide the SMCs to understand the strategies to build lean enabling human capacities and therefore to accelerate the successful lean implementation of SMCs in Sri Lanka. Hence, the findings will pave the path to investigate the organisational and environmental lean capacities for successful lean implementation among SMCs, which will be the focus of the next phase of the research. 


\section{REFERENCES}

Achanga, P., Shehab, E., Roy, R. and Nelder, G., 2006. Critical success factors for lean implementation within SMEs. Journal of Manufacturing Technology Management, 17(4), pp.460-471.

Alves, T.C.L., Azambuja, M.M. and Arnous, B., 2016. Teaching lean construction: a survey of lean skills and qualifications expected by contractors and specialty contractors in 2016. In: Proceedings of the $24^{\text {th }}$ Annual Conference of the International Group for Lean Construction, pp.13-22.

Ankomah, E. N., Ayarkwa, J. and Agyekum, K., 2017. A theoretical review of lean implementation within construction SMEs. In: $6^{\text {th }}$ International Conference on Infrastructure Development in Africa 2017. Africa. pp.71-83.

Antosz, K. and Stadnicka, D., 2017. Lean philosophy implementation in SMEs - study results. Procedia Engineering, 182, 25-32. Doi.org/10.1016/j.proeng.2017.03.107.

Aziz, R.F. and Hafez, S.M., 2013. Applying lean thinking in construction and performance improvement. Alexandria Engineering Journal, 52(2013), pp.679-695.

Basil, A.N.O., 2005. Small and medium enterprises (SMES) in Nigeria: problems and prospects. (Doctoral dissertation, St. Clements University). Available from http://stclements.edu/grad/gradonug.pdf.

Bhasin, S., 2012. An appropriate change strategy for lean success. Management Decision, 50(3), pp.439458.

Chiarini, A. (2012). Lean production: mistakes and limitations of accounting systems inside the SME sector. Journal of Manufacturing Technology Management, 23(5), pp.681-700.

Dora, M. and Gellynck, X., 2015. House of lean for food processing SMEs, Trends in Food Science and Technology, (2015), pp.100-112.

Enemark, S. and Ahene, R., 2002. Capacity building in land management- implementing land policy reforms in Malawi. In FIG XXII International Congress, Washington, D.C. USA, April 19-26.

Flick, U., 2009. An Introduction to Qualitative Research. $4^{\text {th }}$ ed. London: Sage publications.

Green, S.D., Harty, C., Elmualim, A.A., Larsen, G.D. and Kao, C.C., 2008. On the discourse of construction competitiveness. Building Research and Information, 36(5), pp.426-435.

Jin, X. and Ling, F.Y.Y., 2005. Model for fostering trust and building relationships in China's construction industry. Journal of Construction Engineering and Management, 131(11), pp.1224-1232.

Karunasena, G. and Amaratunga, D., 2016. Capacity building for post disaster construction and demolition waste management; A case of Sri Lanka. Disaster Prevention and Management, 25(2), pp.137-153.

Koskela, L.J., Howell, G.A., Ballard, G. and Tommelein, I., 2014. The foundations of lean construction. 211-226. Available at: http://www.researchgate.net/publication/28578914.

Kululanga, G., 2012. Capacity building of construction industries in Sub-Saharan developing countries: A case for Malawi. Engineering, Construction and Architectural Management. 19(1), pp.86-100.

Lopes, C. and Theisohn, T., 2003. Ownership, leadership and transformation: can we do better for capacity development? Earth Scan Publications. UNDP: New York.

Matachi, A., 2006. Capacity building framework; UNESCO-IICBA. United Nations Economic Commission for Africa: Ethiopia.

Miller, C.J., Packham, G., Pickernell, D. and Morse, L., 2002. Increasing Entrepreneurial Capacity Through E-Learning: An Opportunity for Small Construction Firms in South Wales. WEI Working Paper Series Paper 28, Pontyprid; Welsh Enterprise Institute.

OECD., 2012. The challenge of capacity development: working towards good practice. OECD Publication Service: Paris

Preskill, H. and Boyle, S., 2008. A multidisciplinary model of evaluation capacity building. American Journal of Evaluation, 29(4), pp.443-459.

Ranadewa, K.A.T.O., Sandanayake, Y.G. and Siriwardena, M., 2017. What does lean capacity mean? 6th World Construction Symposium 2017 (CIOB), Colombo, Sri Lanka. pp.485-494.

Ranadewa, K.A.T.O., Sandanayake, Y.G. and Siriwardena, M., 2018. Enabling Lean among Small and Medium Enterprise (SME) Contractors in Sri Lanka, In: Proc. $26^{\text {th }}$ Annual Conference of the International. Group for Lean Construction (IGLC), Chennai, India, pp.392-401. 
Rymaszewska, A.D., 2014. The challenges of lean manufacturing implementation in SMEs. Benchmarking: An International Journal, 21(6), pp.987-1002.

Saunders, M., Lewis, P., and Thornhill, A., 2009. Research methods for business students. $5^{\text {th }}$ ed. Essex: Pearson Education Limited.

Sawhney, R. and Chason, S., 2005. Human behaviour based exploratory model for successful implementation of lean enterprise in industry. Improvement Quarterly, 18(2), pp.76-96.

Senaratne, S., Ekanayake, S. and Siriwardena, M., 2010. Lean prefabrication: A sustainable approach. CIB 2010 Wld Cong Proc: Building a Better World, (11), pp.33-44.

Senaratne, S. and Wijesiri, D., 2008. Lean construction as a strategic option: Testing its suitability and acceptability in Sri Lanka. Lean Construction Journal, 4(1), pp.34-48.

Shang, G. and Pheng, L.S. 2014. Barriers to lean implementation in the construction industry in China. Journal of Technology Management in China, 9(2), pp.155-173.

Tezel, A., Koskela, L. and Aziz, Z., 2017. Lean Construction in Small-Medium Sized Enterprises (SMEs): An Exploration of the Highways Supply Chain. In: $25^{\text {th }}$ Annual Conference of the International Group for Lean Construction, (July), pp.845-851.

Zhou, B., 2016. Lean principles, practices, and impacts: a study on small and medium-sized enterprises (SMEs). Annals of Operations Research, 241(1/2), pp.457-474. 